TP Periodica Polytechnica
Civil Engineering

61(2), pp. 176-183, 2017

https://doi.org/10.3311/PPci.9028

Creative Commons Attribution (i)

RESEARCH ARTICLE

\section{Numerical Simulation of Tensile Failure of Concrete in Direct, Flexural, Double Punch Tensile and Ring Tests}

\author{
Vahab Sarfarazi ${ }^{1 *}$, Wulf Schubert ${ }^{2}$
}

Received 17 January 2016; Revised 23 March 2016; Accepted 20 April 2016

\begin{abstract}
The present study considers the tensile strength of concrete samples in direct, flexural, double punch and ring tests using both of the experimental tests and numerical simulation (particle flow code 2D). It determined that which one of indirect tensile strength is close to direct tensile strength. Initially calibration of PFC was undertaken with respect to the data obtained from Brazilian laboratory tests to ensure the conformity of the simulated numerical models response. Furthermore, validation of the simulated models in four introduced tests was also cross checked with the results from experimental tests. By using numerical testing, the failure process was visually observed and failure patterns were watched to be reasonable in accordance with experimental results. Discrete element simulations demonstrated that the macro fractures in models are caused by microscopic tensile breakages on large numbers of bonded discs. Tensile strength of concrete in direct test was less than other tests results. Tensile strength resulted from punch test was close to direct test results. So punch test can be a proper test for determination of tensile strength of concrete in absence of direct test. Other advantages shown by punch tests are: (1) the punch test need less sample size compared with other tests, (2) less material is need for sample preparation, (3) sample preparation is easy and (4) the use of a simple conventional compression press controlled by displacement compared with complicate device in other tests.
\end{abstract}

\section{Keywords}

tensile strength, direct test, flexural test, double punch tensile test and ring test

\footnotetext{
${ }^{1}$ Department of Mining Engineering, Hamedan University of Technology, Mardom street, P.O.B. 65155-579, Iran

${ }^{2}$ Institute for Rock Mechanics and Tunnelling, Technische Universität Graz, Rechbauerstraße 12, A-8010 Graz, Austria

${ }^{*}$ Corresponding author, e-mail: Sarfarazi@hut.ac.ir
}

\section{Introduction}

The Concrete is the most common material used in the construction industry. The use of concrete structural elements can be easily found in buildings, highways/bridges, runways, jetties, etc. Many experimental and theoretical studies have been carried out to determine the tensile strength of concrete [1-12]. Direct tensile test is first method for determination of tensile strength.

However, the tensile strength obtained from the uniaxial tensile test is more reliable than that of other test methods. But this test method requires much more care compared to indirect methods. Particularly, after the production of strong epoxy based adhesives, the uniaxial tensile tests are done with few troubles. Many experimental researches conducted in the past to determine the uniaxial tensile strength failed because of unexpected crushing which occurred as a result of local stress concentrations. Another difficulty in uniaxial tensile tests is that the test specimen is under the influence of moment effects during the tensile test due to eccentricity. The four point flexural test is other method for determination of tensile strength of concrete (Fig. 1).

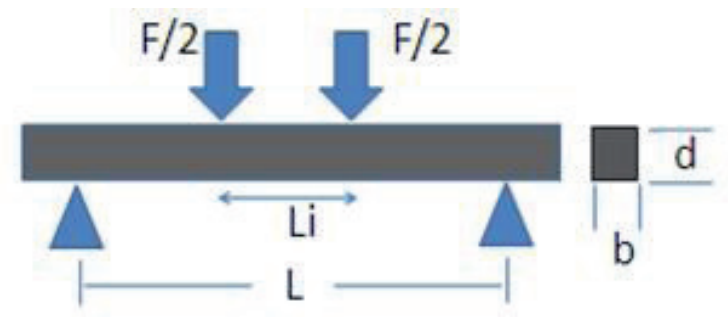

Fig. 1 Four point flexural test [13].

Because of its symmetry, the bending moment is constant between the two load points placed on the top of the specimen. Therefore, the flexural tensile stress is uniform over the thickness. The bottom surface of the specimen between the positions of the two load points is subjected to a constant uniaxial stress field. The nominal flexural strength of a beam under four point bend can be obtained from the beam theory : 
if the loading span is $1 / 2$ of the support span (i.e. $L_{i}=1 / 2 L$ in Fig. 1):

$$
\sigma=\frac{3 F L}{4 b d^{2}}
$$

If the loading span is neither $1 / 3$ nor $1 / 2$ the support span for the 4 pt bend setup (Fig. 1):

$$
\sigma=\frac{3 F\left(L-L_{i}\right)}{2 b d^{2}}
$$

where $\sigma$ is the nominal strength; $F$ is the maximum load, $L_{i}$ is the length of the loading (inner) span, $F$ is the load (force) at the fracture point, $L$ is the length of the support (outer) span, $b$ is width and $d$ is thickness.

According to Elayesh [14] flexural strength provides two useful parameters, namely: the first crack strength, which is primarily controlled by the matrix, and "the ultimate flexural strength or modulus of rupture, which is determined by the maximum load that can be attained.

The double punch test proposed by Chen [15] is other method for determination of tensile strength of concrete (Fig. 2). In this test, a concrete cylinder is placed vertically between the loading platens of the machine and is compressed by two steel punches placed concentrically on the top and bottom surfaces of the cylinder. The specimen splits across many vertical diametric planes similar to the split-cylinder test, but the testing arrangement for the new test may be reduced.

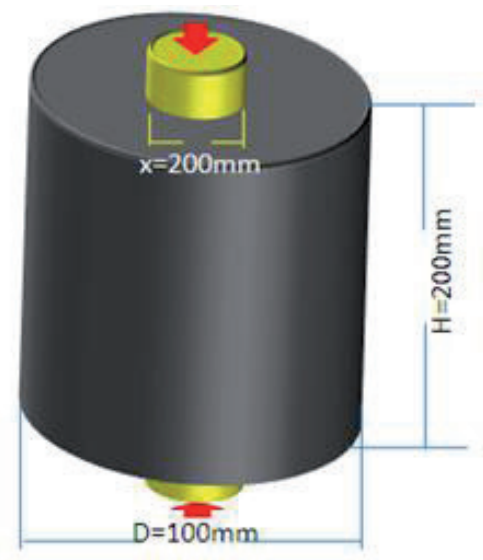

Fig. 2 Double punch test [15].

The relation is proposed by Chen [15]:

$$
\sigma=\frac{0.75 P}{\pi\left(0.3 D H-0.25 x^{2}\right)}
$$

Where, $\sigma$ is tensile strength, $\mathrm{P}$ is failure load, $\mathrm{H}$ is height of specimen, $\mathrm{D}$ is diameter of specimen and $\mathrm{X}$ is diameter of steel punch.

The ring test proposed by Hobbs [16] is other method for determination of tensile strength of concrete (Fig. 3). The ring test has several advantages, such as convenient specimen preparation, simple loading and measurement system, failure starting away from the loading platen, and pure tensile failure mode. From the previous studies of ring tests, the tensile strength was calculated from the maximum tensile stress occurring at the intersections of vertically loaded diameter and the hole.

Pandit [16] proposed an approximate solution:

$$
\sigma=\frac{12 W}{\pi D t}
$$

Where, $\sigma$ is tensile strength, $\mathrm{W}$ is the applied line loading; D and $t$ are the external diameter and thickness of the ring.

In this paper, tensile strength of concrete was measured using direct test, flexural test, double punch test and ring test. Experimental tests and particle flow code were used to determine that which one of indirect tensile strength is close to direct tensile strength.

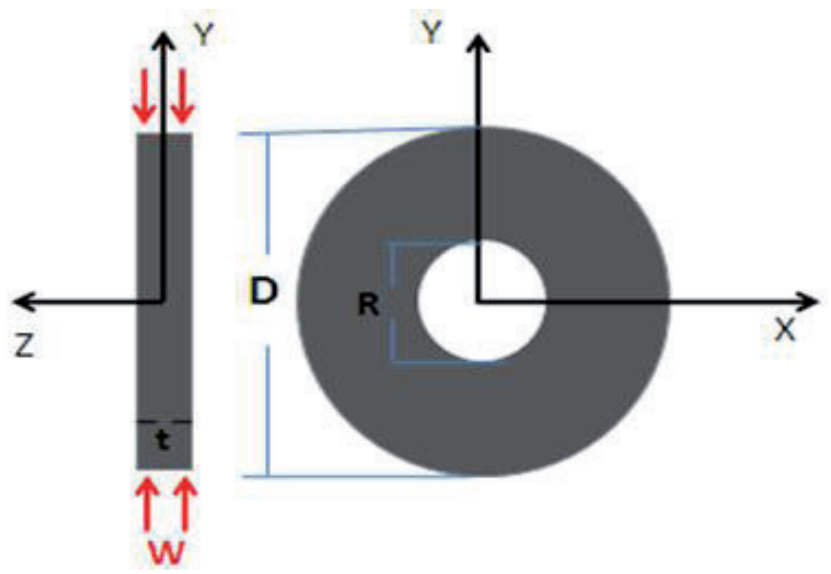

Fig. 3 Ring test [16].

\section{Experimental tests}

\subsection{Samples preparation and testing}

The concrete specimens were prepared from a mixture of two parts water, one part fine sand, and two parts cement. Mixing, casting and curing of specimens were carefully controlled to obtain reproducible properties. Mixing the material constituents was carried out with a blender. The mixed material was cast in different volumes for sampling different types of blocks (Fig 4). Diameters for cylindrical and disc samples were set at $54 \mathrm{~mm}$, with the thickness of $108 \mathrm{~mm}$ and $27 \mathrm{~mm}$, respectively (Fig. 4a, b). Diameters of ring samples were set at $54 \mathrm{~mm}$; diameter of circle hole was $20 \mathrm{~mm}$ with the thickness of $27 \mathrm{~mm}$ (Fig. 4c). Diameters of punch test sample were set at $75 \mathrm{~mm}$ with the thickness of $100 \mathrm{~mm}$ (Fig. 4d). Dimension of flexural test sample was $1200 \mathrm{~mm}^{*} 20 \mathrm{~mm} * 20 \mathrm{~mm}$ (Fig. 4e). Samples kept in geo-mechanics laboratory room for 20 days at $20 \pm 2{ }^{\circ} \mathrm{C}$ before being subjected to mechanical testing. Uniaxial tension test, Brazilian tensile tests, flexural test, punch tensile test and ring test were performed for determining the tensile strength and failure mode of intact model material. 


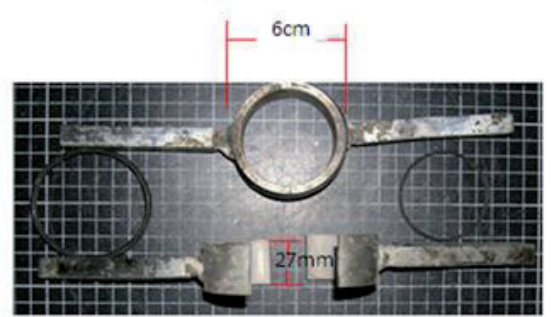

(a)

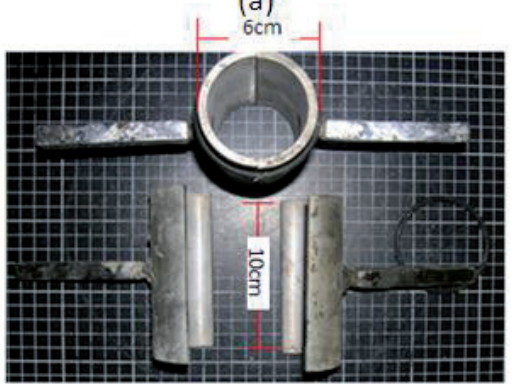

(b)

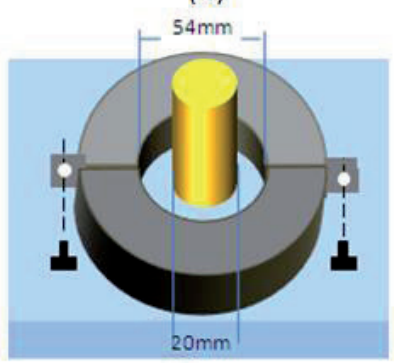

(c)

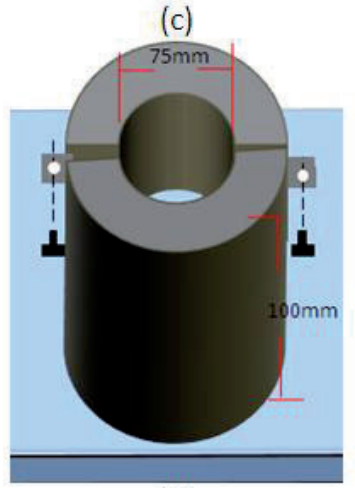

(d)

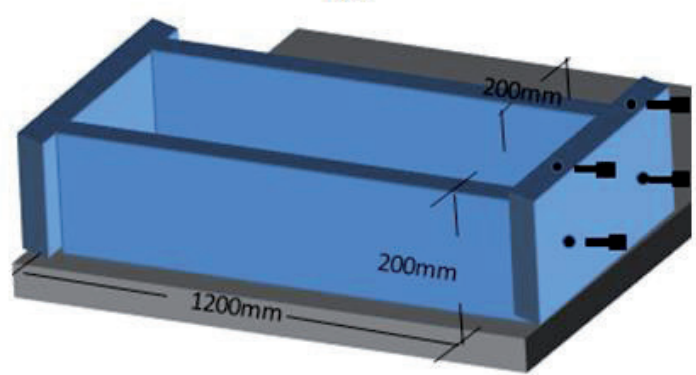

(e)

Fig. 4 Different volumes for sampling different types of blocks used in a) Brazilian test, b) ring test, c) direct test, d) punch tests e) flexural test.

\section{Particle Flow Code}

PFC2D is a two dimensional program to describe the mechanical behavior of collection of circle particles based on the DEM theory introduced by Cundall and Strack [17]. The rigid particles within an assembly displace independently of one another and interact only at each contact points. The calculation cycle in PFC2D is a time-stepping algorithm, in which the motion of each particle is determined by Newton's second law, while the contact force at each contact is updated by forcedisplacement law. When particles come into contact, the contact force is calculated as a function of a relative displacements and specified stiffness. The normal stiffness $\left(\mathrm{K}_{\mathrm{n}}\right)$ is a secant stiffness because it relates the total normal force $\left(\mathrm{F}_{\mathrm{i}}^{\mathrm{n}}\right)$ to the total normal displacement $\left(\mathrm{U}^{\mathrm{n}}\right)$, Eq. (5), while the shear stiffness $\left(\mathrm{K}^{\mathrm{s}}\right)$ is a tangent stiffness because it relates the increment of shear force $\left(\Delta \mathrm{F}_{\mathrm{i}}^{\mathrm{s}}\right)$ to the increment of shear displacement $\left(\Delta \mathrm{U}_{\mathrm{i}}^{\mathrm{s}}\right)$, Eq. (6).

The linear relationships can be expressed as follows [18]:

$$
\begin{gathered}
F_{i}^{n}=K^{n} U^{n} n_{i} \\
\Delta F_{i}^{s}=K^{s} \Delta U_{i}^{s}
\end{gathered}
$$

where $n_{i}$ is the unit normal vector to the contact plane. PFC2D provides two contact-stiffness models: a linear model and a simplified Hertz-Mindlin model. The slip condition at contact with no normal strength is checked by calculating the maximum allowable shear contact force:

$$
F_{\max }^{s}=\mu\left|F_{i}^{n}\right|
$$

Where $\mu$ is the friction coefficient at the contact. If the shear force $\left(\mathrm{F}_{\mathrm{i}}^{\mathrm{s}}\right)$ reaches the maximum allowable shear contact force, slip is allowed to occur by setting the magnitude of $\mathrm{F}_{\mathrm{i}}^{\mathrm{s}}$ equal to $\mathrm{F}_{\text {max }}^{\mathrm{s}}$ using the following equations:

$$
F_{i}^{s} \leftarrow F_{i}^{s}\left(F_{\max }^{s} /\left|F_{i}^{s}\right|\right)
$$

Concrete material are represented by bonding particles together at contact. There are two bonding models supported in PFC2D: a contact-bonded model and a parallel-bonded model. Both bonds approximate the physical behavior of a cement-like substance lying between and joining the two bonded particles. The contact-bond glue is of a vanishingly small size that acts only at the contact point, while the parallel-bond glue is of a finite size that acts over a circular cross-section. Therefore, the contact bond can only transmit a force while the parallel bond can transmit both a force and a moment. Both bonding models can be active at the same time but the existence of a contact bond precludes the slip model, since these last two models describe the constitutive behavior for particle contact occurring at a point. Both types of bond can be broken if their strengths are exceeded. In contact-bonded model, bond breakage may not significantly affect the macro stiffness because contact stiffness is still active even after bond breakage as long as particles are kept in contact. In the parallel-bonded model, however, stiffness is contributed by both contact stiffness and bond stiffness. Thus, bond breakage immediately results in stiffness reduction. In this sense, the parallel-bonded model is known as a more 
realistic model for concrete materials where the bonds may break in either tension or shearing with an associated reduction in stiffness [18]. One of the requirements for the bonded particle model (BPM) is the calibration of the micro-contact parameters to match the macro-scale response.

\subsection{Brazilian Test}

Brazilian test was used to calibrate the tensile strength of specimen in PFC2D model. Adopting the micro-properties listed in Table 1 and the standard calibration procedures (Potyondy and Cundall [19]), a calibrated PFC particle assembly was created. The diameter of the Brazilian disk considered in the numerical tests was $54 \mathrm{~mm}$. The specimen was made of 5,615 particles. The disk was crushed by the lateral walls moved toward each other with a low speed of $0.016 \mathrm{~m} / \mathrm{s}$. The wall velocity was adequate low $(0.016 \mathrm{~m} / \mathrm{s}$ in all tests $)$ to ensure a quasi-static equilibrium. Figure $5 \mathrm{a}$, b illustrate the failure patterns of the numerical and experimental tested samples, respectively. The failure planes experienced in numerical and laboratory tests are well matching. The numerical tensile strength and a comparison of its experimental measurements are presented in Table 2. This table shows a good accordance between numerical and experimental results.

Table 1 Micro properties used to represent the concrete

\begin{tabular}{llll}
\hline Parameter & Value & Parameter & Value \\
\hline Type of particle & disc & Parallel bond radius multiplier & 1 \\
\hline Density & 1000 & $\begin{array}{l}\text { Young modulus of parallel } \\
\text { bond (GPa) }\end{array}$ & 40 \\
\hline Minimum radius & 0.27 & Parallel bond stiffness ratio & 1.7 \\
\hline Size ratio & 1.56 & Particle friction coefficient & 0.4 \\
\hline Porosity ratio & 0.08 & $\begin{array}{l}\text { Parallel bond normal strength, } \\
\text { mean (MPa) }\end{array}$ & 25 \\
\hline Damping coefficient & 0.7 & $\begin{array}{l}\text { Parallel bond normal strength, } \\
\text { SD (MPa) }\end{array}$ & 2 \\
\hline Contact young & 40 & $\begin{array}{l}\text { Parallel bond shear strength, } \\
\text { mean (MPa) }\end{array}$ & 25 \\
\hline modulus (GPa) & 1.7 & $\begin{array}{l}\text { Parallel bond shear strength, } \\
\text { SD (MPa) }\end{array}$ & 2 \\
\hline Stiffness ratio & &
\end{tabular}

Table 2 Brazilian tensile strength of physical and numerical samples.

\begin{tabular}{ll}
\hline Physical tensile strength $(\mathrm{MPa})$ & 4.5 and 4.7 \\
\hline Numerical tensile strength $(\mathrm{MPa})$ & 4.5 \\
\hline
\end{tabular}

\subsection{Direct Tensile Test}

After calibration of PFC2D, direct tensile tests were simulated by creating a box model in the PFC2D (by using the calibrated micro-parameters) (Fig. 6a). The PFC specimen had the dimensions of $75 \mathrm{~mm} \times 100 \mathrm{~mm}$. A total of 11,179 disks with a minimum radius of $0.27 \mathrm{~mm}$ were used to make up the shear box specimen. Two rectangular zones with length of $30 \mathrm{~mm}$ and thickness of $20 \mathrm{~mm}$, was removed from the right and left sides of the model. After model preparation, four semi circle loading wall were installed in contact with the hole wall (Fig. 6a). Tensile loading was applied to the sample by moving the upper and lower walls in the positive side of Y-direction and in the opposite side of Y-direction, respectively. The Tensile force was registered by taking the reaction forces on the wall 3 in Fig. 6 a.

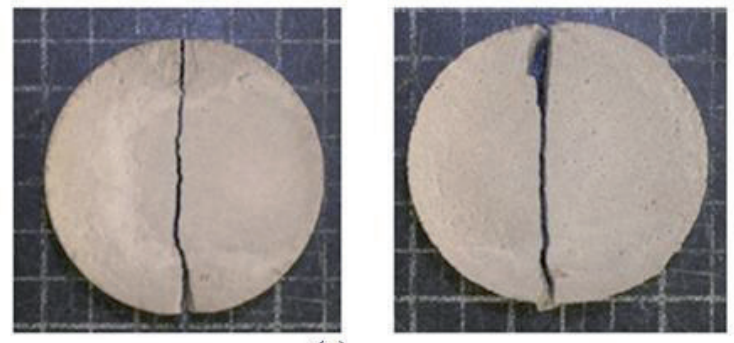

(a)

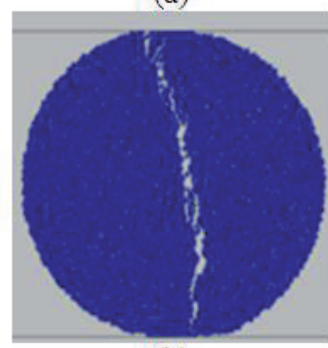

(b)

Fig. 5 failure pattern in a) physical sample [20], b) PFC2D model.

\subsection{Double punch test}

Double punch test was simulated by creating a box model in the PFC2D (by using the calibrated micro-parameters) (Fig. 6b). The PFC specimen had the dimensions of $100 \mathrm{~mm} \times 75 \mathrm{~mm}$. A total of 15818 disks with a minimum radius of $0.27 \mathrm{~mm}$ were used. After model preparation, two loading wall were installed in the middle and in contact with the model (Fig. 6b). The length of loading wall walls $20 \mathrm{~mm}$. tensile loading was applied to the sample by moving the lower and upper walls in the positive side of Y-direction and in the opposite side of Y-direction, respectively. The Tensile force was registered by taking the reaction forces on the wall 1 in Fig. 6 b.

\subsection{Ring test}

Ring test was simulated by creating a circle model in the PFC2D (by using the calibrated micro-parameters) (Fig. 6c). Diameter of the Ring disk was $54 \mathrm{~mm}$. a circle with diameter of $20 \mathrm{~mm}$ was removed from the model. The specimen was made of 4312 particles. The disk was crushed by the lateral walls moved toward each other. The Tensile force was registered by taking the reaction forces on the wall 1 in Fig. 6c.

\subsection{Flexural Test}

Flexural Test was simulated by creating a box model in the PFC2D (by using the calibrated micro-parameters). The PFC 


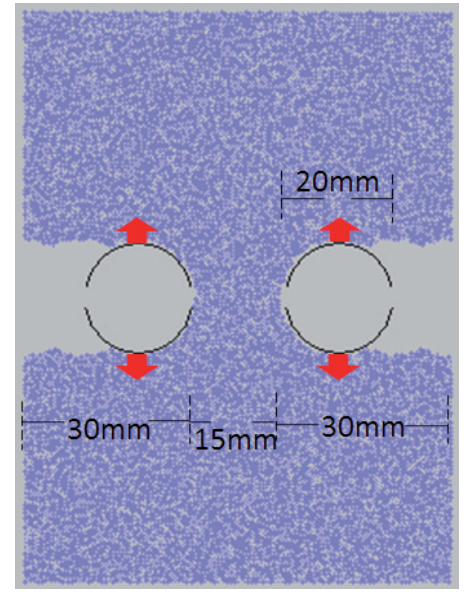

(a)

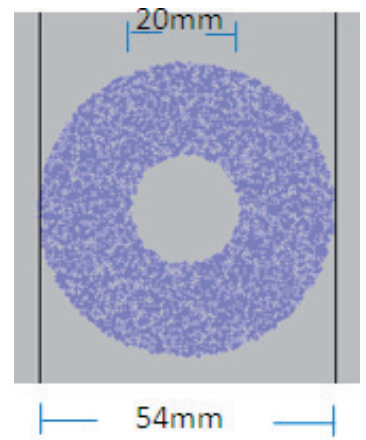

(c)

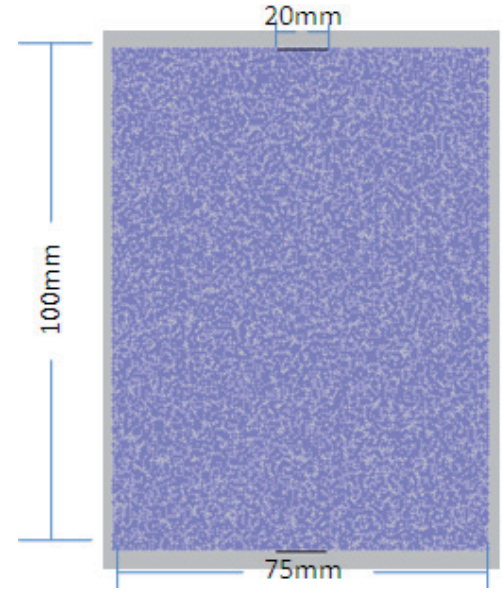

(b)

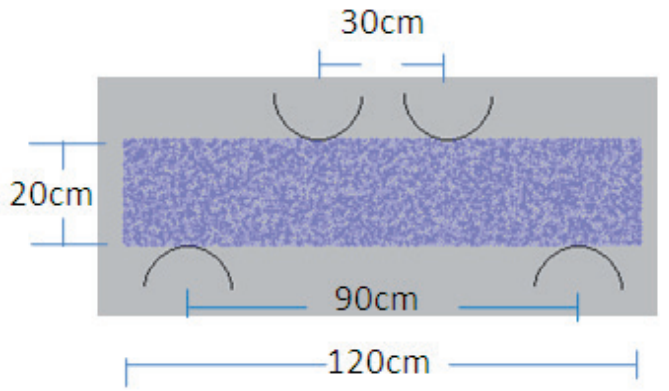

(d)

Fig. 6 Specification of numerical model, a) direct tensile test, b) punch test, c) ring test, d) flexural test.

specimen had the dimensions of $1200 \mathrm{~mm} \times 20 \mathrm{~mm}$. A total of 6326 disks with a minimum radius of $0.27 \mathrm{~mm}$ were used. After model preparation, four semi circle loading wall were installed in contact with the model (Fig. 6d).

The spacing between the lower walls was $90 \mathrm{~mm}$ and the spacing between the upper walls was $30 \mathrm{~mm}$. tensile loading was applied to the sample by moving the lower and upper walls in the positive side of Y-direction and in the opposite side of Y-direction, respectively. The Tensile force was registered by taking the reaction forces on the wall 3 in Fig. $6 \mathrm{~d}$.

\section{Tensile failure mechanism}

\subsection{Comparison between Failure patterns in numerical models and experimental one}

Figure 7-10 shows progress of cracks in direct test, punch test, ring test and flexural test respectively. In each figure, the results of numerical simulation and experimental test have been shown. Black lines and red lines represent the tensile cracks and shear cracks, respectively. From Fig. 7a, its clear that under direct test, the numerical model gets broken from the middle with diagonal tensile cracks what happens in experimental test (Fig. 7b).

Figure 8a shows that under punch test, two wedge of material performed at top and bottom of the model. Then model gets broken from the middle by one vertical tensile fracture what happens in experimental test (Fig. 8b). Figure 9a shows that under ring test, model gets broken by one horizontal tensile fracture what happens in experimental test (Fig. 9b).

Figure 10a shows that under flexural test, model gets broken by one vertical tensile fracture what happens in experimental test (Fig. 10b).

It's to be noting that, from each experimental test two similar samples where prepared and tested under special condition. In some cases where the results were undesirable, the third sample was tested. Table 3 shows the average value of these data.

\subsection{Comparison between tensile strength in numerical models and experimental one}

Table 3 shows a comparison between the tensile strengths for direct test, punch test, flexural test and ring test in both of the numerical and experimental tests.

Table 3 Results of direct test and punch test flexural test and ring test.

\begin{tabular}{lllll}
\hline & direct test & punch test & flexural test & ring test \\
\hline $\begin{array}{l}\text { Tensile strength in } \\
\text { numerical simulation } \\
(\mathrm{MPa})\end{array}$ & 4 & 5.5 & 6.2 & 5.9 \\
\hline $\begin{array}{l}\text { Tensile strength in } \\
\text { experimental test } \\
(\mathrm{MPa})\end{array}$ & 3.7 & 4.9 & 5.5 & 5.5 \\
\hline
\end{tabular}




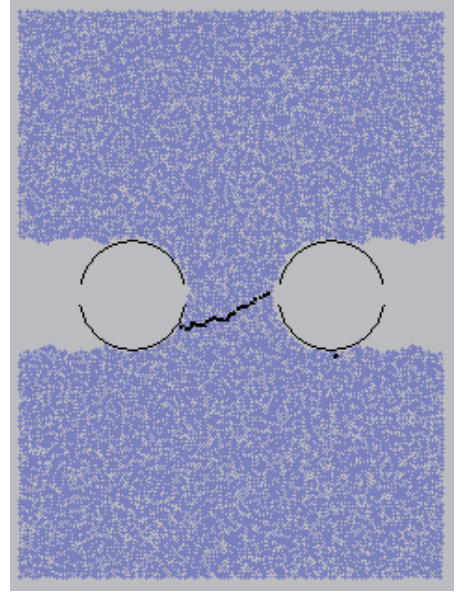

(a)

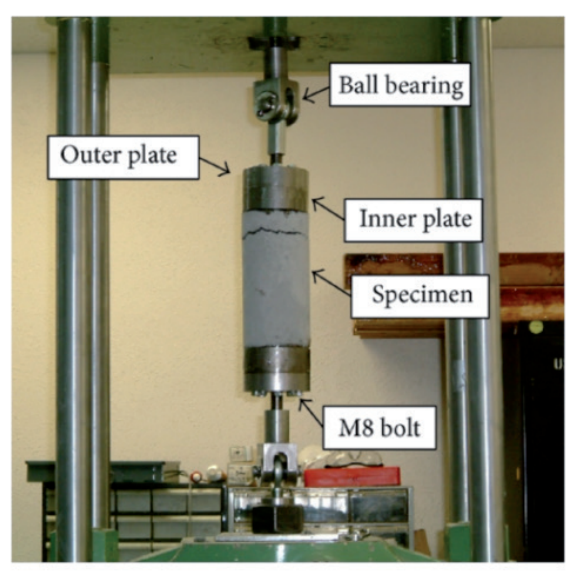

(b)

Fig. 7 Failure pattern in direct test, a) numerical simulation, b) experimental test.

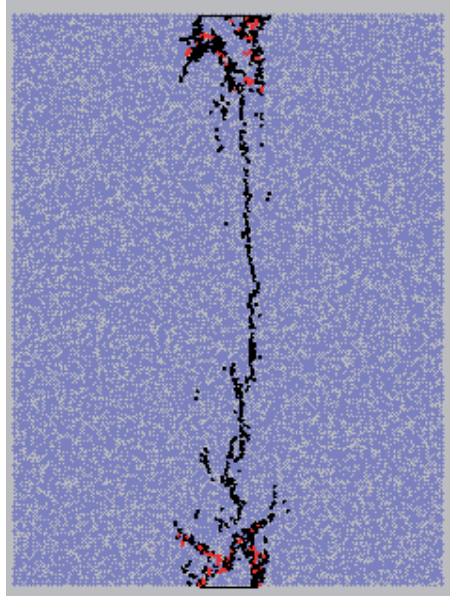

(a)

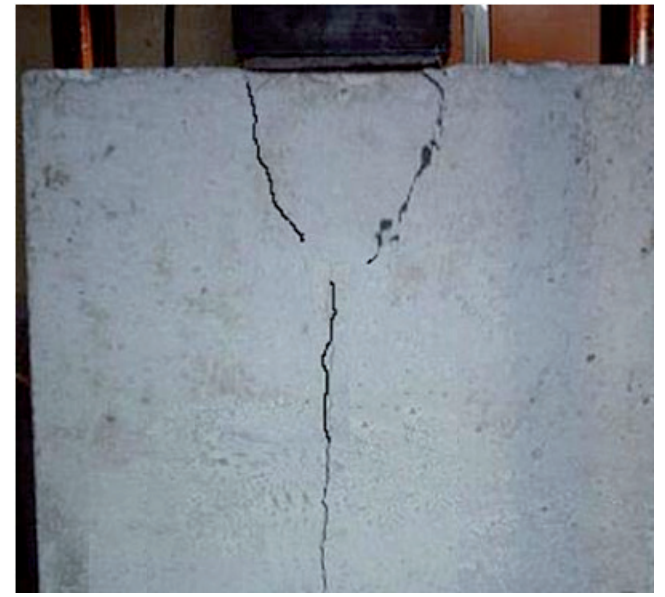

(a)

Fig. 8 Failure pattern in punch test, a) numerical simulation, b) experimental test.

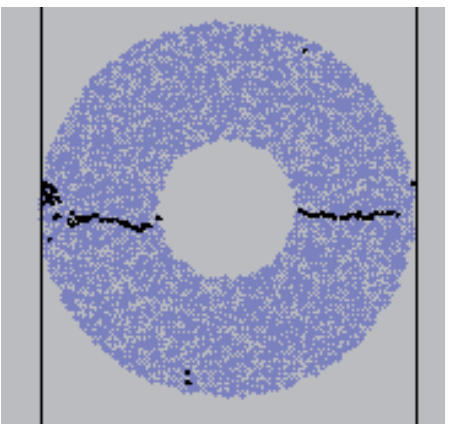

(a)

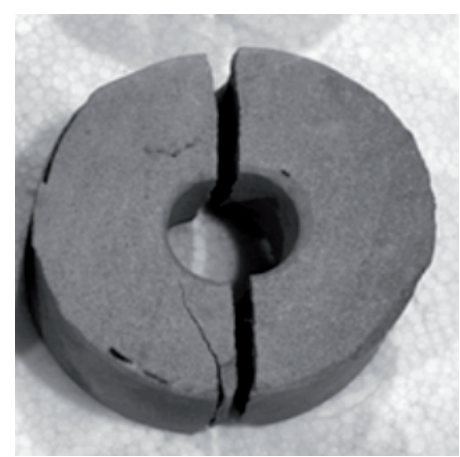

(b)

Fig. 9 Failure pattern in ring test, a) numerical simulation, b) experimental test. 


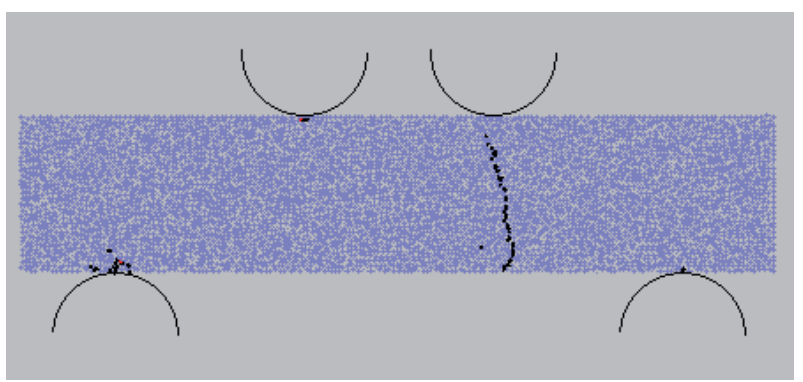

(a)

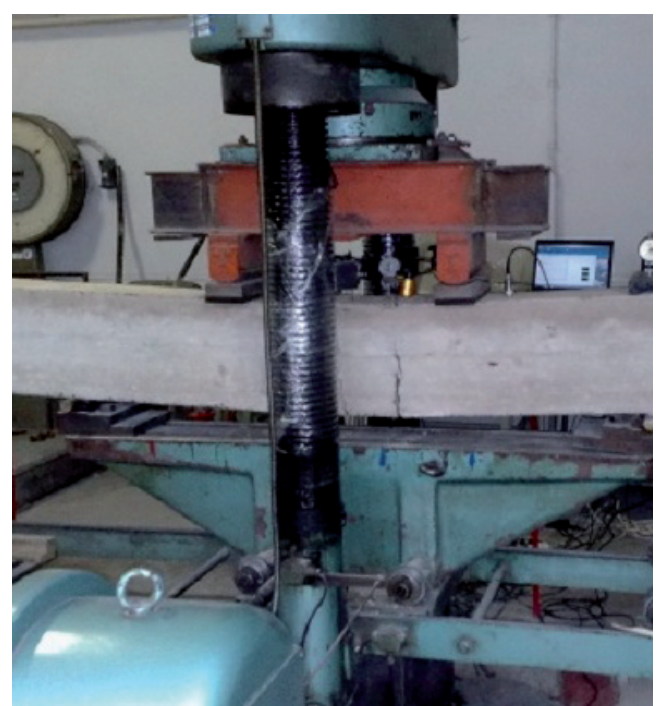

(b)

Fig. 10 Failure pattern in flexural test, a) numerical simulation, b) experimental test.

Results from numerical and experimental tests show that, tensile strength obtained from experimental tests were less than numerical one. This is due to the presence of micro cracks and micro pore in the physical samples which lead to lower tensile strength. Direct tension test yields the lowest strength values (Table 3) due to high tensile stress distribution on failure surface. Ring test yields the highest strength values (Table 3 ). Figure 11 shows tensile strength error obtained in different tests related to direct tensile test. The relative errors are calculated by division of difference between tensile strength obtained by various tests (xi) and direct tensile strength (a) to direct tensile strength $([(x i-a) / a] \times 100)$.

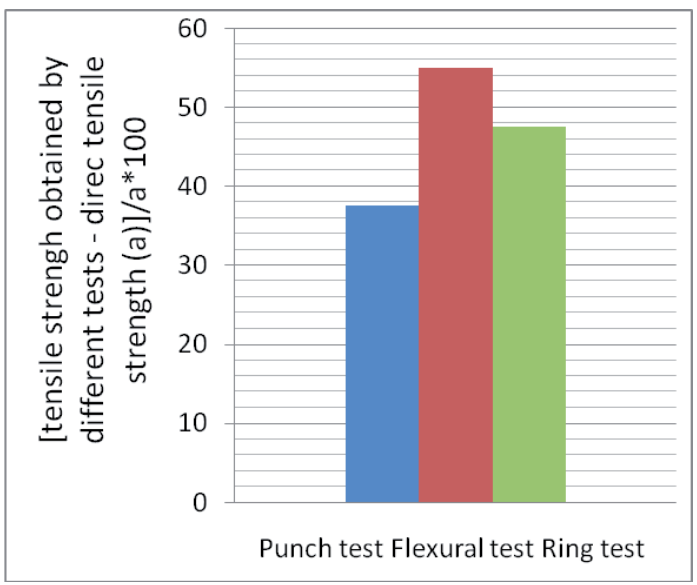

Fig. 11 Tensile strength error in punch test, flexural test and ring test related to direct tensile test.

The results shows that tensile strength relative error in punch test, flexural test and ring test was $37.5 \%, 55 \%$ and $47.5 \%$, respectively. Whereas tensile strength obtained by punch test is nearest to direct tensile strength therefore punch test is a proper test for determination of tensile strength of concrete in absence of direct tensile test.
From other point of view direct tensile test method requires much more care compared to indirect methods. Particularly, after the production of strong epoxy based adhesives, the uniaxial tensile tests are done with few troubles. Another difficulty in uniaxial tensile tests is that the test specimen is under the influence of moment effects during the tensile test due to eccentricity. The sample preparation in four point test and ring test are too difficult but it's easy in punch test. Direct tensile test apparatus was consisted of four probes such as inner plate, outer plate, M8 bolt and ball bearing (Fig. 7b). The assemblage of these probes is time consuming and its number is too large. The four point test apparatus was consisted of four probes such as two lower loading segments and two upper loading segments (Fig. 10). The punch test apparatus was consisted of two small loading plates (Fig. 8) and ring test apparatus was consisted of two curves loading plates which inserted upper and lower of the specimen. From above finding It can be concluded that punch test need simple probes for testing and therefore it is a practical test for determination of tensile strength of concrete.

Other advantages shown by by punch tests are: (1) the punch test need less sample size compared with other tests, (2) less material is need for sample preparation, (3) sample preparation is easy and (4) the use of a simple conventional compression press controlled by displacement compared with complicate device in other tests.

\section{Conclusions}

The tensile failure behavior of concrete in indirect tests (flexural, double punch tensile and ring tests) and direct test has been investigated using experimental test and numerical simulations.

By using numerical testing, the failure process was visually observed and failure patterns were watched to be reasonable in accordance with experimental results. Discrete element 
simulations demonstrated that the macro fractures in models are caused by microscopic tensile breakages on large numbers of bonded discs. Tensile strength of concrete in direct test was less than other tests results. Tensile strength resulted from punch test was close to direct test results. So punch test can be a proper test for determination of tensile strength of concrete in absence of direct test. Other advantages shown by punch tests are: (1) the punch test need less sample size compared with other tests, (2) less material is need for sample preparation, (3) sample preparation is easy and (4) the use of a simple conventional compression press controlled by displacement compared with complicate device in other tests.

\section{Refrences}

[1] Wan Ibrahim, M. H., Hamzah, A. F., Jamaluddin, N., Ramadhansyah, P. J., Fadzil, A. M. "Split Tensile Strength on Self-compacting Concrete Containing Coal Bottom Ash." Procedia - Social and Behavioral Sciences. 195, pp. 2280-2289. 2015. DOI: 10.1016/j.sbspro.2015.06.317

[2] Tian, Y., Shi, S., Jia, K., Hu, S. "Mechanical and dynamic properties of high strength concrete modified with lightweight aggregates presaturated polymer emulsion." Construction and Building Materials. 93, pp. 11511156. 2015. DOI: 10.1016/j.conbuildmat.2015.05.015

[3] Luong, M. P. "Tensile and shear strength of concrete and rock." Engineering fracture mechanic. 35(1-3), pp. 127-135. 1990.

[4] Zollo, R. F. "Fiber-reinforced concrete: an overview after 30 years of development." Cement \& concrete Composites. 19(2), pp. 107-122. 1997. DOI: $10.1016 / \mathrm{S} 0958-9465(96) 00046-7$

[5] Silva, R. V., de Brito, J., Dhir, R. K. "Tensile strength behaviour of recycled aggregate concrete." Construction and Building Materials, 83, pp. 108-118. 2015. DOI: 10.1016/j.conbuildmat.2015.03.034

[6] Gerges, N. N., Issa, C. A., Fawaz, S. "Effect of construction joints on the splitting tensile strength of concrete." Case Studies in Construction Materials. 3, pp. 83-91. 2015. DOI: 10.1016/j.cscm.2015.07.001

[7] Liu, X., Nie, Z., Wu, S., Wang, C. "Self-monitoring application of conductive asphalt concrete under indirect tensile deformation" Case Studies in Construction Materials. 3, pp. 70-77. 2015.

DOI: $10.1016 /$ j.cscm.2015.07.002

[8] Mobasher, B., Bakhshi, M., Barsby, C. "Backcalculation of residual tensile strength of regular and high performance fiber reinforced concrete from flexural tests." Construction and Building Materials. 70, pp. 243253. 2014. DOI: 10.1016/j.conbuildmat.2014.07.037
[9] Kim, J. J., Reda Taha, M. "Experimental and Numerical Evaluation of Direct Tension Test for Cylindrical Concrete Specimens." Advances in Civil Engineering. 2014, Article ID 156926, 8 pages. DOI: $10.1155 / 2014 / 156926$

[10] Rocco, C., Guinea, G. V., Palans, J., Elices, M. "Review of the splittingtest standads from a fracture mechanics point of view." Cement and Concrete Research. 31(1), pp. 73-82. 2001. DOI: 10.1016/S0008-8846(00)00425-7

[11] Gomez, J. T., Shukla, A., Sharma, A. "Static and dynamic behavior of concrete and granite in tension with damage." Theoretical and Applied Fracture Mechanics. 36(1), pp. 37-49. 2001. DOI: 10.1016/S0167-8442(01)00054-4

[12] van Mier, J. G. M., van Vliet, M. R. A. "Uniaxial tension test for the determination of fracture parameters of concrete: state of the art." Engineering Fracture Mechanics. 69(2), pp. 235-247. 2002. DOI: 10.1016/S0013-7944(01)00087-X

[13] Soutsos, M. N., Le, T. T., Lampropoulos, A. P. "Flexural performance of fibre reinforced concrete made with steel and synthetic fibres." Construction and Building Materials. 36, pp. 704-710. 2012.

DOI: 10.1016/j.conbuildmat.2012.06.042

[14] Elayesh, S. M. "Performance of laterite aggregate concrete." Universiti Teknologi Malaysia. Faculty of Civil Engineering. 2009. URL: http:// eprints.utm.my/11401/1/SalemMohamedElayeshMFKA2010.pdf

[15] Chen, W. F. "Double Punch Test for Tensile Strength of Concrete." Journal of the American Concrete Institute. 67(1), pp. 993-995. 1970.

[16] Pandit, G. S. "Discussion on the paper, concrete rings for determining tensile strength of concrete." ACI Journal. October, pp. 847-848, 1970.

[17] Cundall, P. A., Strack, O. D. L. "A discrete numerical model for granular assemblies." Geotechnique. 29(1), pp. 47-65. 1979. DOI: 10.1680/geot.1979.29.1.47

[18] Itasca Consulting Group Inc. Itasca Consulting Group Inc. PFC3D (particle flow code in 3dimensions) version 3.0. Minneapolis: Itasca; 2003.

[19] Potyondy, D. O., Cundall, P A. "A bonded-particle model for rock." International Journal of Rock Mechanics and Mining Sciences. 41(8), pp. 1329-1364. 2004. DOI: 10.1016/j.jijmms.2004.09.011

[20] Sarfarazi, V., Ghazvinian, A., Schubert, W., Nejati, H. R., Hadei, R. "A New Approach for Measurement of Tensile Strength of Concrete." Periodica Polytechnica Civil Engineering. 60(2), pp. 199-203. 2016. DOI: 10.3311/PPci.8328 